\title{
BREVE ENSAYO SOBRE CRISIS Y RELACIONES INDUSTRIALES *
}

\author{
Antonio Martín Artiles \\ Pere Jódar Martínez \\ (Centre d'Estudis Socials)
}

«[...] La estrategia de Ia "larga marcha" de las instituciones no languidece en absoluto, pese a la dureza cada vez mayor de la situación económica y social, provocada por la actual acumulación de tendencias de la crisis fiscal y a la crisis de acumulación. El sueño del triunfo de la sociedad sobre el capital y el Estado está vivo y vigoroso.»

(O'Connor, 1973: 333)

\section{INTRODUCCION}

La «crisis» actual ha sido analizada básicamente desde el punto de vista económico. Por el contrario, en este ensayo pretendemos enfocar la problemática desde el ángulo de las relaciones laborales. Esto es, el laberinto de ideas que se entrecruzan dentro del concepto genérico «crisis» quedaría inexplicado si no se aborda o interpreta como un cambio en las relaciones de fuerza entre capital y trabajo. De ahí que nuestra lectura de la crisis ligue, hipotéticamente, sus manifestaciones globales con las que aparecen en el interior de la empresa. In suma, este ensayo tiene como objeto últi-

* Estudio de seguimiento tealizado en el Centro de Estudios Sociales de Barcelona. Asimismo constituye un marco teórico de referencia para una investigación que estamos llevando a cabo. Dicho estudio tiene un enfoque microsociológico con una propuesta de realizar "catas» en las relaciones laborales, la descentralización productiva y la organización del trabajo de dos empresas multindcionales; una de un sector sometido a reestructuración sectorial y otra de un sector estable. 
mo ofrecet un marco térico a quienes se asoman a estudiar las cuestiones laborales y el controvertido mundo sindical.

\section{Entre el Estado del bienestar $y$ el «sistema de relaciones industriales»}

El boom económico europeo operado después de la segunda guerra mundial trajo como consecuencia un cambio estructural en la fuerza de trabajo (Gough, 1979: 152). El auge económico bajo la égida del capital norteamericano y el impulso desde el Estado keynesiano alcanzó cotas sin precedentes: la economía se internacionalizó, a la par que hacía más interdependientes los estados-nación, se «socializaba» la producción y el consumo se abría a amplias capas de la población. Pero la expansión del mercado y la rápida acumulación de capital tropezaba con los conflictos industriales que salpicaban la geografía europea (Arrighi, 1980: 20).

A este proceso se añadió la dinámica de la lucha de clases, que ha generado históricamente la introducción de medidas de bienestar social. Así, frente a la oleada de conflictividad apoyada en un crecimiento de la «fuerza estructural» del trabajo o "poder negociador obrero en el lugar de trabajo» (Arrighi, 1980: 24), 'se han contrapuesto las políticas de bienestar social o «dinero de rescate» para ahogar una amenaza potencialmente peli-

GráfICO 1

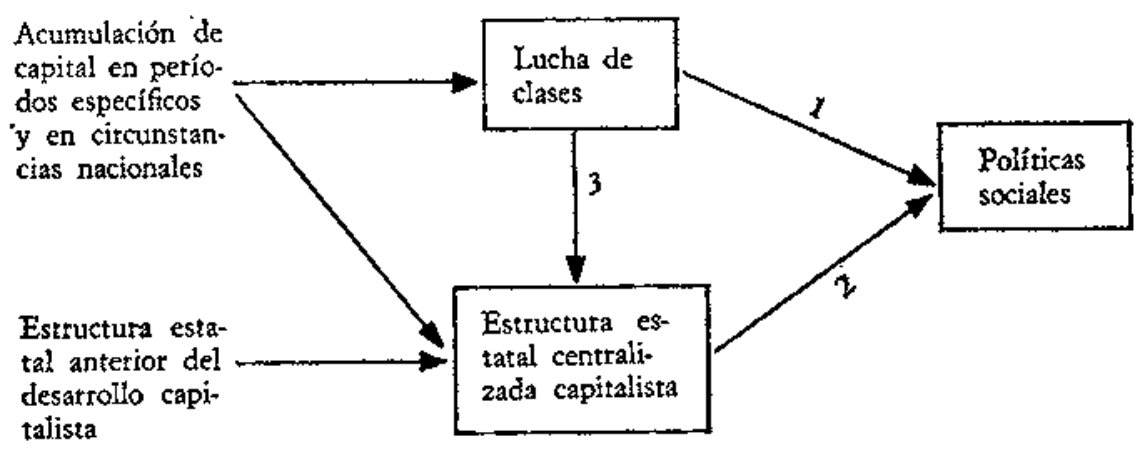

Fuente: Esping-Anderson, Friedland y O. Wright, „Kapitalistaten, núm. 4/5, 1976. Citado por Ian Gough, 1979.

1. La alta tasa de sindicalización de postguerra registrada en los países europeos es un hecho sin precedentes: $70 \%$ en Bélgica, $90 \%$ en Suecia, $50 \%$ en Gran Bre. taña, $42 \%$ en Alemania Occidental, etc. (Fuente: F. Pérez Amotós-E. Rojo: Guía Sindical 82-83, Ed. Unión Sindical Obrera.) 
grosa para el sistema político y económico del capitalismo avanzado. Con ello el poder institucional no sólo buscaba la «legitimación» sino también la reproducción en condiciones de «artnonía de intereses» (Gough, 1979: 145).

En suma, la articulación por una parte de la fuerza de trabajo organizada sindicalmente y por otra de la "política de rescate» desarrollada por el poder institucionalizador fue conformando lo que posteriormente se ha conocido como Estado del bienestar, cuyo origen es contradictorio y ambiguo. Esquemáticamente podemos representar los factores influyentes con el gráfico 1.

Naturalmente este nuevo fenómeno era, en parte, la continuación lógica del modelo keynesiano basado en crecimientos salariales capaces de titar de la demanda mediante el consumismo. Requisito para el funcionamiento suave del sistema. En resumidas cuentas, la complejidad de la nueva situación edificada y amparada bajo el Estado del bienestar abre un intertogante: ¿acaso es un medio de represión e integración, o bien ha sido la conquista de un "salario social» para el movimiento obrero?

En continuación directa de este proceso dialéctico del conflicto industrial se ha ido fraguando un modelo paradigmático de relaciones laborales. Este modelo teorizado desde una vertiente juxídica y sociológica pone el acento en lo institucional; de forma que el paradigma o «sistema de relaciones industriales» se asienta sobre tres clases de actores: «a) obreros y sus organizaciones, $b$ ) empresazios y sus organizaciones y $c$ ) organismos gubernamentales que se ocupan del lugar de trabajo y de la comunidad labotal» (Dunlop, 1959: 21). Fuera de este juego tripolat (sindicatos-Estadoempresarios) y jerarquizado no puede legitimarse poder ni negociación en el terreno laboral; por lo tanto la legitimación del sistema capitalista avanzado pasará a ser congruente o compatible con el subsistema de relaciones industriales. Ello ha dado pie a una ideología o «entendimientos compartidos» para la tesolución institucional del conficto en un contexto estable de inter. acción de los actores, con la finalidad de mantener unido al sistema capitalista bajo un proyecto racional y ordenado (Dunlop, 1959: 351-359).2 Si bien

2. Hyman (1975) criticó justamente esta vertiente del conflicto, que sólo contempla sus aspectos formales y descuida los procesos informales, y que en el conjunto de las relaciones industriales impone su dinámica por encima del sistema cerrado de intertelaciones descrito por T. Dunlop.

A las dificultades propias de esta concepción antepone Hyman otra definición de las relaciones de trabajo, subrayando su carácter de "procesos de control sobre las mismas, cono relación continua y cambiante que nunca puede ser individualizada eficazmente en una norma formal» (p. 22). Este proceso incluirá tanto la reglamentación del trabajo como el control de la organización y acción colectiva de los trabaja- 
este modelo ha servido para respaldar la acumulación hacia la década de los cincuenta y sesenta, por el contrario, ya en la década de los setenta el mantenimiento del equilibrio y del ritmo de acumulación ha resultado cada vez más costoso por cuanto el Estado del bienestar acarrea un incremento del gasto público cada vez más insostenible. La presión fiscal, de un lado, y de otro el alza de los costos del trabajo, debido a la fuerza estructural de los trabajadores, ha ralentizado el crecímiento de la tasa de ganancias. Esto significa una doble contradicción con la lógica del libre mercado:

1) Si nos limitamos a observar el crecimiento del gasto público, tenemos que el mismo ha crecido en mayor proporción que el producto intetior bruto en los países capitalistas avanzados (Gough, 1979: 163). Por añadidura su financiación ha debido hacerse en base al déficit público (inflacionista) (S. Holland, 1980: 92). En otras palabras, la asignación de tal cantidad de recursos afecta necesariamente a la estructura de la demanda del sistema, así como al funcionamiento general del mismo.

2) En segundo lugar, la política de expansión de la demanda tiende a ser inherentemente inflacionista ya que el mecanismo clásico del metcado «deja de funcionar y no son las fuerzas impersonales del mercado sino las relaciones de producción dominantes (entre capital monopolista y sindicatos) las que dominan el reparto de los recursos económicos, la estructura salatial y la distribución de las rentas entre la clase obrera y la capitalista» (O'Connor, 1973: 46). En otras palabras, sobreviene la «crisis» ya que el Estado del bienestar se opone a la lógica de acumulación capitalista pues de alguna manera actúa para «satisfacer las necesidades» y «extender los derechos», lo que conlleva un gasto público a gran escala que afecta al mismo crecimiento económico (Gough, 1979: 66-67). Con ello el sistema de producción capitalista adquiere rigidez y limitaciones que suponen la

dores, así como a otras relaciones conflictuales producto de un conflicto de intereses entre la sociedad y la industria, íntimamente ligados a las contradicciones del sistema capitalista.

El modelo de Dunlop, basado en el paradigma normativo funcionalista, tropieza, a partir de la crisis estructural del sistema capitalista, con severas dificultades a su ya problemática lógica de explicación interna de los fenómenos industriales. Por esto la propuesta de Hyman, basada en los procesos de control, hace posible una perspec. tiva dialéctica de aproximación, que permite captar el conjunto de relaciones del mundo del trabajo en un proceso total de cambio y fluctuación. Pero no sólo ello, sino que además conecta de forma directa con propuestas más generales, provenientes de la economia política, por ejemplo, que subrayan la importancia del control sobre los procesos políticos y económicos y sobre el Estado en particular. 
caída de la tasa de ganancia. Paralelamente la lógica del mercado se ve crecientemente condicionada por la intervención del Estado o bien regulada a partir de la acción de los actores sociales... El paradigma entra en contradicción con la producción capitalista.

¿Cómo tesponde el capital a este estrangulamiento? ¿Cómo intenta te. cuperar la tasa de ganancia? De alguna forma la problemática planteada se deriva del modelo de acumulación de postguerra. La interdependencia de la política de bienestar/subsistema de relaciones industriales/sistema capitalista, refleja la dinámica de la sociedad capitalista avanzada y la lucha de clases producida en su seno. Por ello no puede calificarse la actuación de los sindicatos como simplemente «reformista e integradora»; en todo caso se trata de un juego de fuerzas más complejo, en el cual si bien el trabajo ha aumentado su fuerza organizativa, también el capital ha sabido responder paulatinamente. Grosso modo ha intentado remodelar la relación de fuerzas estructuradas impulsando todo aquello que, por el contratio, fomenta la heterogeneidad, la individualización y atomización de las relaciones laborales. Esta acción del capital la podemos agrupar en dos grandes bloques: descentralización productiva e innovaciones tecnológicas.

\section{Descentralización productiva y recomposición begemónica del capital}

Estos dos elementos (descentralización y tecnologías) parece que se conjugan con objeto de lograr una mayor movilidad y libertad del capital en el uso de la fuerza de trabajo. A la postre ello conduce a una estrategia para flexibilizar el mercado de trabajo.

\section{Gráfico 2}

\section{División internacional del trabajo}

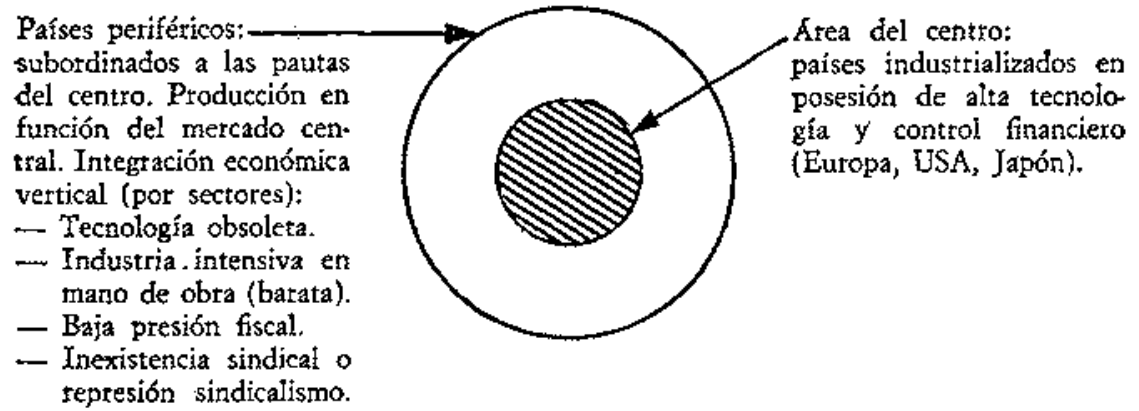


Esta dinámica en la descentralización productiva halia expresión no sólo en la división internacional del trabajo, sino también en el interior de los países industrializados. En el plano internacional se vertebra un mundo cuya estructura podemos resumir en el establecimiento de un grupo de países industrializados cuya producción tiene una más alta composición otgánica de capital y que posee el control del capital y la texnología. Mientras que, por el contrario, en la periferia tiende a ubicarse las industrias intensivas en mano de obra cuya actividad productiva se hace en forma subordinada y en función de las necesidades del centro (véase gráfico 2).

Igualmente, en los países desarrollados parece organizarse una estructura económica dual. Dividida en sectores productivos diferenciados por su poder económico en el mercado (I. Santillana, 1980: 176): 1) por un lado, en el centro del sistema se asientan las empresas con características monopolistas: posesión de recursos financieros, tecnología avanzada, estabilidad y predicción de la demanda, integración vertical de los procesos productivos y que ofrecen empleos más o menos estables, formación y promoción interna; 2) en la perifetia se hallan las empresas carentes de poder económico y que desarrollan sus actividades de forma «competitiva y subordinada». Sus principales rasgos serían: falta de recursos financieros, tecnología atrasada, escasa diversificación de sus productos, subordinación a la actividad central, líneas de producción no integradas y que ofrecen empleos inestables. Por consiguiente esta dicotomía también da lugar a un fraccionamiento en el tipo de empleo.

\section{GRÁFICO 3}

\section{Tendencia estructura económica}

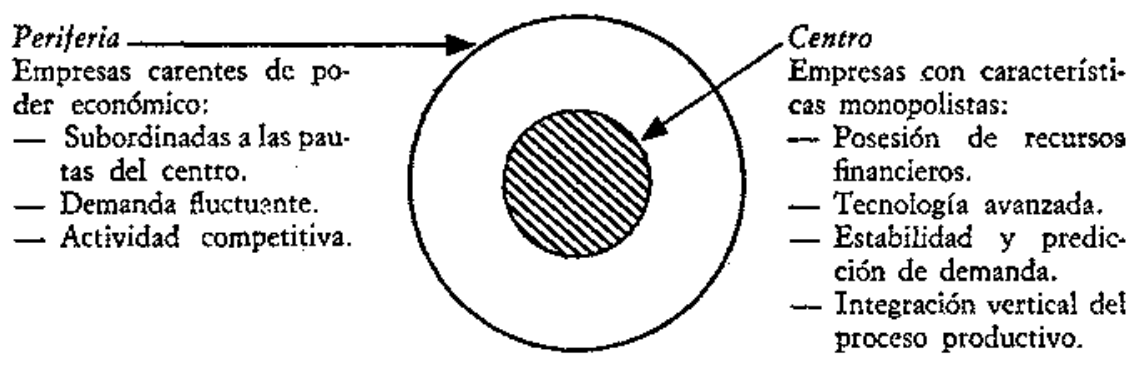

En esta misma línea y bajo el mismo esquema, podemos dibujar la creciente dualidad que se manifiesta en el mercado de trabajo: 1) en el centro o mercado primatio, como le llaman algunos autores, domina 
un sistema «formal» de relaciones de trabajo, protegido legalmente por la intervención de los actores sociales (empresarios, sindicatos y gobierno); y 2) en la periferia o mercado secundario, que se caracteriza por un «sistema salvaje» de relaciones labotales y donde se encuentran las formas de trabajo a domicilio, trabajadores autónomos, trabajos a tiempo parcial, contratos temporales, trabajo a destajo, etc. (Casassus, 1980: 16).

Esta segmentación, estimulada además por el desempleo estructụral, se convierte, pues, en un instrumento que permite lograr mayor ductilidad en la contratación del empleo (Trentin, 1980: 122-123). Dicha idea halla elocuencia y concreción en el interior de la empresa (y aquí está una de nuestras hipótesis «nudo»: ¿acaso no está artículado todo este proceso desde la escala internacional hasta la empresa?). En el interior de la empresa (incluso en las «grandes», que según nuestro modelo se hallan en el «centro») el caballo de batalla para recuperar la tasa de ganancia pasa por lograr la flexibilidad en la fuerza de trabajo; o sea, el establecimiento de «plantillas acordeón» que permita adaptar mejor la producción a las ondas del ciclo económico y a las fluctuaciones de la demanda. En este contexto se explican fenómenos como la aparición de dos tipos de trabajadores: «internos» y «externos» (Coriat, 1980: 85-102). Unos con carácter fijo y otros petmanentes pero «no fijos». Otro aspecto notorio es el tema de movilidad geográfica y movilidad funcional en los puestos de trabajo (por ejemplo, administrativos que pasan a producción y viceversa) o bien la polivalencia de la mano de obra, así como las nuevas formas de organización del trabajo (Dadoy, 1980: 74-84). (Véase gráfico 4.) En defnitiva, intuimos que se trata de un proceso común que liga a los niveles mencionados (d.i.t., estructura económica nacional, mercado de trabajo y empresa). Esta dinámica afecta de forma articulada a diversos sectores por la quiebra del paradigma clásico y por la emersión de nuevos elementos en las relaciones sociales de producción, lo que puede suponer la definición de un nuevo modelo.

Por lo tanto se opera un cambio cualitativo que afecta a distintos niveles y que impacta a los sindicatos en su asentamiento natural, otrora relativamente homogéneo y donde se entretejía la solidatidad.

En cuanto a las tecnologías, su introducción en el proceso productivo ha dado lugat a un salto cuantitativo y cualitativo considerable. Dentro de la lógica de racionalización industrial se tiende a sustituir progresivamente el trabajo por el capital (Cacace: 1978), especialmente con la aplicación de los mictoprocesadores (ISE: 1979) y la robotización a los bienes de equipo, favoreciendo el esquema tiempo-máquina frente al de tiempohombre anterior. En relación directa es muy posible que en la década de los 80 se conozca un relativo crecimiento sin aumento sensible del empleo, 
introducido en la organización empresarial y en el proceso productivo por los monopolios y las corporaciones transnacionales (Norman, 1981: 55-59).

GRÁFICO 4

\section{Empresa del «centro» que utiliza mercado de trabajo secundario}

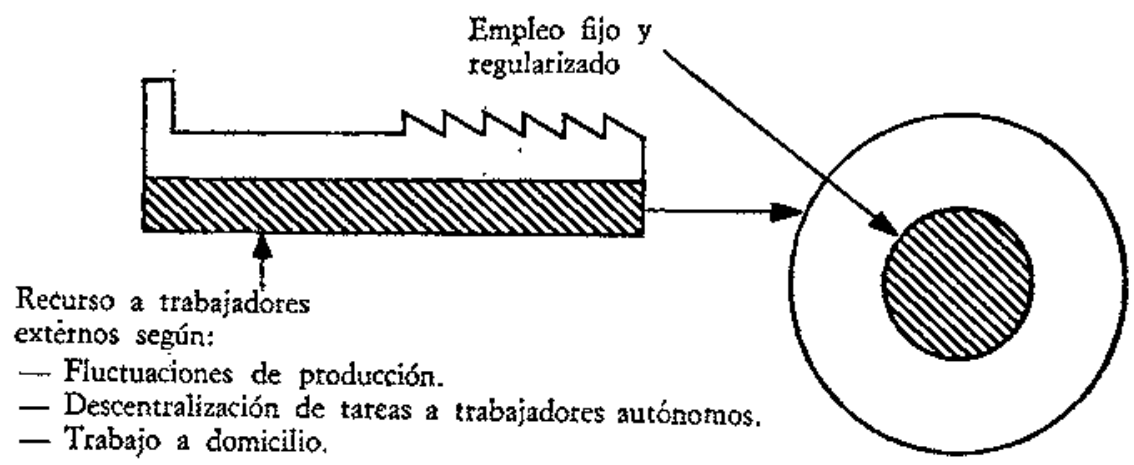

Todo ello conlleva una reducción de los márgenes de maniobra de los sindicatos y del empresariado no ligado al capital monopolista (Estivill-Martín Artiles, 1981: 14), así como al fraccionamiento en la composición orgánica de la fuerza de trabajo. Paralelamente las nuevas técnicas y organización del trabajo tienden a aislar, segmentar e individualizar las relaciones de trabajo desde la misma empresa, cuestión que incide y deteriora la solidaridad vertebrada de la acción sindical vertical (de rama o federación de actividad), con lo cual el conflicto tiende a localizarse y limitarse territorialmente, quebrándose así no sólo la presión vertical de la fuetza de trabajo, sino también la acción sindical desde una perspectiva más global e institucional. Paradójicamente todo ello ocurre precisamente en el momento en que el capital transnacional articula y coordina su acción a escala internacional: creando de esta forma una objetiva ligazón dependiente en la clase trabajadora de los diferentes países donde opera el capital multinacional. Ligamen sutil que, en contrapunto, es dificultoso contestar desde las actuales estructuras organizativas (asentadas sobre el Estado-nación) y estratégicas del sindicalismo. 


\section{Los sindicatos en la encrucijada}

Las semillas de la «crisis» han sido germinadas precisamente durante el boom económico y el paralelo cambio en las relaciones de fuerza entre capital y trabajo. Desde una óptica sindical, dicha crisis afecta a tres aspectos importantes: a la composición interna de la clase trabajadora, a las relaciones sindicato-Estado y a la representatividad estratégica sindical.

1. La segmentación de los mercados de trabajo parece ser parte «de ta estrategia de empleadores que operan en un contexto de movilidad internacional del capital y de la mano de obra» (Casassus, 1980: 22). Además los mercados de trabajo nacionales no sólo tienden a presentar una creciente dualidad, sino que asimismo se hallan estratificados, conformándose grandes distancias en los salarios y condiciones de trabajo entre los dis. tintos sectores. ¿Cómo incorporar en una plataforma teivindicativa común a sindicatos de sectores tan dispares como los de sanidad y textill? Es más, hoy las confederaciones sindicales encuentran acogidas en su seno a sindicatos (o federaciones de ramo) muy distintos y a los cuales es difícil implicar en una estrategia o en la dirección de un programa común. Las telaciones de estos órganos suelen ser en muchos casos más bien formales y con escasos vínculos (Sylos Labini, 1974: 105).

En este sentido resulta elocuente que los sindicatos europeos y espa* noles se fijen como objetivo una estrategia para la reunificación de la fuerza de trabajo. ${ }^{3}$ No obstante, este objetivo llega tarde puesto que hasta los años 76 y 77 la crisis era analizada en términos básicamente económicos. Se insistía en su carácter de depresión coyuntural y en la inflación provocada por el aumento de las materias primas, especialmente el petróleo. Se otorgaba cierta confianza a la aplicación de medidas convencionales de política económica como posibles soluciones (Rosanvaillon, 1977: 69-70). De hecho las soluciones no han llegado precisamente por esa vía. En cual-

3. «Unificar la fuerza del trabajo para cambiar la sociedad» fue el siogan del Congreso de la Confederación General Italiana del Lavoro, en 1981. En parecidos términos se ha guiado el congreso de la CISL. (Véase «Crónica Información Laboral», núm. 1, 1982, Batcelona.) En el caso español tenemos las insistencias estratégicas de CCOO y USO en la misma dirección. Sin embargo, no dejan de ser definiciones globales planteadas con la misma tardanza con la cual los sindicatos han interpretado el «tipo» de crisis que se estaba etitretejienco. Los contenidos de la reunificación de la fuerza de trabajo se resumen en:

- Reducción abanico salarial.

- Reducción categorías profesionales.

- Reducción atomización convenios.

- Articulación convenios a rivel estatal. 
quier caso la realidad del fraccionamiento de la clase obrera se manifiesta hasta en el interior de la empresa, «allí donde las garantías relativas de empleo y de salarios están mejor aseguradas, en términos de contratos y convenios; es donde se puede observar el recurso más sistemático a empresas exteriores de alquiler de mano de obra y a la contratación de auxiliares reclutados al margen de todo marco $y$ de todo estatuto" (Coriat, 1979: 200). Estas frases son expresión elocuente de la división trabajadores internos - trabajadores externos.

Por añadidura, la fuerza de trabajo está fragmentada por enormes di. ferencias de cualificaciones, de sueidos y de poder de negociación de determinados estamentos y profesiones en contrapunto a otras matginales (y cuyo número se acrecienta). En este contexto diverso se explica la gran cantidad de pequeños sindicatos independientes que luchan entre sí. Incluso se encuentran colectivos sindicales de este tipo a niveles de empresas puntas, cuyas condiciones de trabajo son superiores a las de otras empresas del mismo sector.

Tơo ello trae a colación el peligro corporativista que acecha al mundo laboral y a la sociedad en general. La amenaza constante de cerrarse y/o ensanchar los intereses y privilegios de colectivos sectoriales o de empresas, con poder de negociación contractual, pone de relieve la inclinación a la ruptuta de la lógica de clases y, en cambio, a «refeudalizar» la sociedad mediante el quebrantamiento de la coordinación borizontal; a la vez que se acentúa la coordinación vertical. De ahí que para algunos sociólogos la

- ocupación pase a ser la unidad ptincipal de la desigualdad y no la de clase (Giner, 1982).

Incluso puede darse la paradoja de que los trabajadores afiliados y protegidos por la acción sindical sean precisamente aquellos núcleos que tienen un trabajo estable en empresas «del centro». $Y$ en sentido inverso quedarían fuera del sindicalismo aquellos espacios «dispersos», «heterogéneos», con escasa concentración de la mano de obra, con dificultades de vertebración y coordinación estratégica: pequeñas empresas de comercio al detall, trabajadores a domicilio, trabajadores a tiempo parcial, etc. (es decir, espacios de nueva marginación). ¿Y acaso ya no está sucediendo eso? ¿Acaso el amplio abanico salarial que presentan estos sectores sociales no es un reflejo de su situación precaria y «secundaria»? ¿Es el corporativismo una consecuencia implícita en la lógica de mercado? ¿Es posible hoy una política sindical de reducción de las desigualdades cuando en un mismo sector productivo se haila la constante dualidad de trabajadores «del centro» y «trabajadores periféricos» ? ${ }^{4}$ En este caso ¿qué sentido tiene la definición «sindicato de

4. Cabe apuntar que durante la transición a la democracia los sindicatos españoles 
clase»? ¿Es factible una estrategia de «clase» que incorpore al mismo titmo reivindicativo la diversidad de colectivos de obreros y empleados?

No cabe duda de que en este contexto fragmentado la clase trabajadora halla enormes dificultades para mantener los derechos adquiridos. En cambio el capital halla más facilidades para desmantelat el Estado del bienestar, reducir el gasto público e imponer los criterios de vałor de cambio y de mercado.

2. Los interrogantes esbozados en el punto anterior acartean un nuevo planteamiento para los sindicatos. Esto es, su relación con el Estado.

La pugna de los sindicatos por mantener la política del bienestar y el «salario social» para los amplios sectores de trabajadores sin poder de negociación contractual ni defensa colectiva, incide en la discusión acerca de la visión tradicional que de la izquierda martiene el Estado. Éste no es únicamente un instrumento de dominación de clase cuya finalidad es asegurar las condiciones de la acumulación. El Estado moderno deviene en un objeto del conflicto de clases donde los «actores» sociales luchan por el reparto del «botín». En una palabra, la cuestión que se plantea es el control social del Estado, y no tanto la legitimidad y la integración en el orden social (O'Connor, 1973: 320-323).

Por consiguiente el forcejeo se traduce en las presiones para reprivatizar el Estado del bienestar, de un lado, y de otro en mantener $y / o$ ampliar los derechos a modo de «paraguas» para proteget a los sectores más débiles de los trabajadores. Otra manifestación del conflicto se produce en los acuerdos globales sindicatos-Estado-empresarios («pactos sociales») donde se discuten simultáneamente el salario privado, el salario social, el consumo colectivo, el control de la inflación y la dirección de los impuestos (Gough, 1979: 263). Y también otro motivo de pugna lo constituye la discusión de los presupuestos del Estado en la medida en que constituye un consumo social.

Si bien en la década de los 80 el problema estriba en mantener esos derechos que la clase trabajadora ha conquistado, la cuestión subsiguiente es igualmente contradictoria. ¿Cómo y con qué fuerzas mantenerios cuando la «fuerza estructural del trabajo» se halla «deshilachada», fragmentada?

se har empeñado en reducir las desigualdades intersectoriales y por tamaño de empresa. De ahí que la negociación colectiva fuera presidida de una estrategia basada en los aumentos lineales que caracterizó el periodo 1974-1978. Sin embargo, fute imposible mantener la mistna lógjca; así, a partir de 1979, la masa salarial bruta pasará a destinarse a los aumentos proporcionales y con ello a renunciar a la reducción de las distancias que separan a los trabajadores. (Consúltese dossier Balance Negociación Colectiva 1977-82, «Crónica Información Laboral», Barcelona, 1982.) 
¿Cómo negociar institucionalmente con fuerzas que se disipan? ¿Siguen siendo válidas las actuales formas organizativas de los sindicatos; no supone Ia vía institucional configurar un sindicalismo «sin trabajadores»? ¿Cómo representar a la heterogeneidad de intereses y conjugar las reivindicaciones de los diferentes colectivos? ¿Qué debe primar: los intereses generales del país, los intereses de clase o los intereses particulares de los segmentos?

3. Las preguntas planteadas en el punto anterior desembocan en tratar la crisis de representatividad que afecta a los sindicatos. ${ }^{5}$ Cómo tepresentar y dar voz sin modificar las peticiones de la base de los distintos segmentos?

En líneas generales las dificultades de representación pivotan aquí: en la fase de transmisión de las peticiones o reivindicaciones y su articulación con la de otros grupos sociales para insertarlas en un programa coherente y a largo plazo frente a la crisis (Regini, 1981: 63). Esta cuestión dibuja dos hipótesis de intervención:

1) Estrategia institucional, primando las relaciones «por arriba» y enfocada a la resolución de los intereses generales; lo cual comporta una línea de actuación más o menos moderada para mantener el equilibrio institucional. Esta opción ha de modificar necesariamente la petición de las bases, aunque la dialéctica con la misma no cobra la importancia de antaño. Ya que el proceso de identificación no es fundamentalmente ideológico. El consenso y la identificación le vendrán dados por la vía de los incentivos selectivos, los servicios a afiliados y el poder de negociación contractual. De esta forma el sindicato tiende a colocarse en un espacio interclasista.

Pero tiene un triple riesgo: $a$ ) la posible transformación burocrática con dificultades para movilizar a las bases; $b$ ) el peligto de no poder controlar (por falta de instrumentos) los datos teales de la economía y no cumplir los objetivos selectivos propuestos (salario social, prestaciones, etcé-

5. A pesar de que los sindicatos (a diferencia de los partidos) poseen instrumentos (asambleas, conflictos de empresa y huelgas) para vexificar el grado de consenso puntualmente entre sus bases, la crisis de representatividad supone un cuestionamiento đe su papel: corganización de clase, institución o asociación? (P. Craveri, 1982: 37-47).

Por otra parte, la crisis de representatividad en los sindicatos españoles es más grave, por cuanto han tenido que organizatse en una situación de transición en ucrisis». Ello se refleja de forma contundente en el alto grado de abstención en las elecciones sindicales. Por ejemplo, en 1980 sólo se eligió al $49 \%$ de los delegados potencialmente elegibles, mientras que los votantes supusieron tan sólo unos tres millones, cuando el número de asatariados es de algo más de nueve millones. (Estivill - Martín Artiles, 1982: 77-82.) 
tera) debido a las fluctuaciones del ciclo económico; y c) el corporativismo (organizaciones) que mediatizaría el conflicto de clase (Giner, 1981: 91).

2) Estrategia de fábrica o retorno al «oficio del sindicalista». Desde esta óptica el sindicato no se hace cargo de los intereses generales ni de políticas concertativas. En cambio, sí transmite la «petición de la base» sin modificarla. No obstante se puede presentar el peligro de explosión de las reivindicaciones particularistas que (amparadas en un lenguaje de apariencia radical) lleven a atmentar las distancias entre los segmentos del mercado de trabajo. En otras palabras, puede dar pie al mentado corporativismo y a la jerarquización de privilegios en cotos cerrados.

Y por último queda un tema más «difuso»: ¿es posible una estrategia de clase? ¿Es posible combinar la petición de los segmentos con una telativa modificación y una actitud tendencialmente antagónica al capital, que conlleve una identificación y vinculación del sindicato con las bases desde el plano ideológico y de la acción?

En resumidas cuentas, la «crisis» tiene una lectura más allá de las intexpretaciones estrictamente económicas y exige un conocimiento más preciso de los cambios que están sucediendo en las relaciones laborales desde el nivel de empresa. El reto está ahí: ¿será posible mantener la composición orgánica de la clase trabajadora a fin de impulsar el desartollo de las políticas sociales y controlar el Estado del bienestar? ¿O acaso se conforman unas relaciones laborales segmentadas bajo la égida del corporativismo y estratificadas en función de la fuerza y poder de negociación de cada uno de los múltipies colectivos de trabajadores, guiados a la postre por la lógica de mercado?

En el trasfondo de todo ello está la crisis del igualitarismo. Si los sindicatos quieren superarla desde una perspectiva activa y de transformación progresista, han de plantearse dos cuestiones.

La primera es la insuficiencia de sus actuales formas organizativas, asentadas fundamentalmente en la industria, precisamente cuando el sector en crecimiento es el terciario, y abtirse hacia los espacios de difícil vertebración (parados, trabajadores a tiempo parcial, temporeros, a domicilio, mujer, jóvenes, etc.). Es decir, hacia las áreas sociales, en línea con lo que se entiende como estructura borizontal.

La segunda cuestión supone asumir un rol muy discutido: intervenir en la política de rentas (y no sólo en reivindicar el salatio directo), en la política económica y preocuparse por las cuestiones de la acumulación de capital. De ello dependerá que el igualitarismo siga siendo un ideal de cambio o una simple fantasía en una sociedad profundamente desigual y corpora- 
«Papers»: Revista de Sociologia

tiva. Es más, el sindicato debe devenir en sujeto politico e instrumento social de control sobre el Estado; máxime si consideramos que la "crisis» sitúa los problemas al día, en el terreno del corto plazo y menos a largo plazo. 


\section{BIBLIOGRAFIA UTILIZADA}

Arrighi, Giovanni. «La crisis en relación con la fuerza estructural de la clase obrera» (pp. 18-27), en AA. VV., La izquierda ante la crisis económica mundial, Ed. Pablo Iglesias, Madrid, 1980 (186 pp.).

Cacace, Nicola: «Democracia difficil senza occupazione» (pp. 141-193), en N. Cacace, L. Frey, R. Moresse. Lavorare meno per lavorare tutti, Edi. zioni Lavoro, Roma, 1978 (238 pp.).

Casassus, Cecilia. «Del modelo neoclásico a las teorías de la segmentación del mercado de trabajo" (pp. 9-22), en AA. VV., Mercado de trabajo y relaciones de producción, «Rev. Sociología del Trabajo», núm. 3/4, Ediciones Queimada, Madrid, 1980 (216 pp.).

Craveri, Piero. Clase, istituzione o associazione? (pp. 37.44), en «II Pro. getto», núm, 8, Roma, 1982 (111 pp.).

Colin, Norman. La nueva revolución industrial (pp. 55-59), en «Facetas», núm. 4, Madrid, 1981.

Coriat, Benjamin. «Diferenciación y segmentación de la fuerza de trabajo en las industrias de proceso» (pp. 85-102), en AA. VV., Debate sobre la cualificación del trabajo, en «Rev. Sociología del Trabajo», núm. 2, Ed. Zero, ZYX, Madrid, 1980 (209 pp.).

Coriat, Benjamin. El taller y el cronómetro, Ed. Siglo XXI, Madrid, 1982 (204 pp.).

Dadoy, Mireille. «La polivalencia obrera y su remuneración (pp. 65-84), en AA. VV., Debate sobre la cualificación del trabajo, en «Rev. Sociología del Trabajo», núm. 2, Ed. Zero, ZYX, Madrid, 1980.

Dunlop, John T. Sistema de relaciones industriales, Ediciones Península, colección «Homo sociologicus», Barcelona, 1978 (359 pp.).

Estivill, J., Martín Artiles, A. «Crisis y sindicatos: nuevas estrategias para nuevos tiempos» (pp. 7-28), en AA. VV., Crisis económica y relaciones de trabajo, en «Rev. Sociología del Trabajo», núm. 6, Ediciones Quei. mada, Madrid, 1981 (127 pp.).

Estivill, J., Martín Artiles, A. I sindicati spagnoli al bivio (pp. 77-82), en «Il Progetto», núm. 10/11, Edizioni Lavoro, Roma, 3982 (119 pp.).

Gough, Ian. Economía politica del Estado del bienestar, H. Blume Ediciones, Madrid, 1982 (304 pp.). 
Giner, Salvador. La agonia de la sociedad civil (pp. 87-96), en «Leviatán», núm. 5, Madrid, 1981 (144 pp.).

Giner, Salvador. «La sociogénesis de la desigualdad y la estructura de las sociedades corporativas», inédito, Brunel University, Londres, 1982.

Hyman, Richard. Relaciones industriales. Una introducción marxista, H. Blume Ediciones, Madrid, 1981 (237 pp.).

Holland, Stuard. "Una nueva planificación como respuesta a la crisis» (pp. 87-103), en AA. VV., La izquierda ante la crisis económica mundial, Ed. Pablo Iglesias, Madrid, 1980 (186 pp.).

Institut Syndical Européen (ISE). L'impact de la microelectronique sur l'emploi en Europe Occidentale dans les années 80, Bruselas, ISE, octubre 1979 (180 pp.).

O'Connor, James. La crisis fiscal del Estado, Ediciones Penínsuła, colección «Homo Sociologicus», Barcelona, 1981 (341 pp.).

Regini, Marino. «La crisis de representatividad de los sindicatos de clase» (pp. 51-69), en AA. VV., Crisis económica y relaciones de trabajo, en «Rev. Sociología del Trabajo», núm. 6, Ediciones Queimada, Madrid, 1981 (128 pp.).

Rosanvallon, Pierre. Crisi du capitalisme et estratégies syndicales en Europe (pp. 59-78), en «CFDT Aujourd'hui», núm. 27, París, 1977.

Santillana del Bartio, Ignacio. «Paro y estructura ocupacional de la población activa» (pp. 176-200), en AA. VV., Clase obrera y orden económico, en «Papeles de Economía Española», núm. 8, Ed. Confederación de Cajas de Ahorro, Madrid, 1980 (286 pp.).

Sylos Labini, P. «Sindicatos obreros y sindicatos de las capas medias» (pp. 101-107), en Ensayo sobre las clases sociales, Ediciones Península, colección «Homo Sociologicus», Barcelona, 1981 (172 pp.).

Trentin, Bruno. "Los sindicatos ante la crisis en Italia» (pp. 116-130), en La izquierda ante la crisis económica mundial, Editorial Pablo Iglesias, Madrid, 1981 (186 pp.). 